performance-based measures of standing balance and lower limb motor control function in subjects with TKA should be considered.

References:

[1] Si, H. B., Zeng, Y., Zhong, J., et al. (2017). The effect of primary total knee arthroplasty on the incidence of falls and balance-related functions in patients with osteoarthritis. Scientific reports, 7(1), 1-9.

[2] Moutzouri, M., Gleeson, N., Billis, E., et al. (2017). The effect of total knee arthroplasty on patients' balance and incidence of falls: a systematic review. Knee Surgery, Sports Traumatology, Arthroscopy, 25(11), 3439-3451.

[3] Hill, K. D., Bernhardt, J., McGann, A. M., et al. (1996). A new test of dynamic standing balance for stroke patients: reliability, validity and comparison with healthy elderly. Physiotherapy Canada, 48(4), 257-262.

Disclosure of Interests: None declared

DOI: 10.1136/annrheumdis-2020-eular.4853

\section{AB1285-HPR ACCELEROMETRIC ASSESSMENT OF PHYSICAL PERFORMANCE DURING THE SIT-TO-STANDTEST IN PATIENTS WITH KNEE OSTEOARTHRITIS}

S. Fellous ${ }^{1}$, H. Rkain ${ }^{1}$, S. Afilal ${ }^{1}$, J. Moulay Berkchi ${ }^{1}$, T. Fatima Zahrae ${ }^{1}$, A. Ilham ${ }^{1}$, T. Latifa ${ }^{1}$, S. Aboudrar ${ }^{2}$, T. Dakka ${ }^{2}$, L. Errguig ${ }^{2}$, A. Jniene ${ }^{2}$, M. Bakkali ${ }^{2}$, F. Allali ${ }^{1} .{ }^{1}$ Faculty of Medicine and Pharmacy of Rabat, Mohammed V University, Rabat, Department of Rheumatology B, El Ayachi Hospital, Rabat, Morocco; ${ }^{2}$ Faculty of Medicine and Pharmacy of Rabat, Mohammed V University, Rabat, Physiology Laboratory, Rabat, Morocco

Background: Knee osteoarthritis is a major public health issue that causes chronic pain and functional limitation.

Objectives: This study aims to evaluate physical performance in knee osteoarthritis by clinical tests and accelerometer measurements, and investigate the relationship between physical perfomance alteration and clinical parameters.

Methods: This is a cross-sectional study, included 40 patients with knee osteoarthritis $(100 \%$ female, average age $57.6 \pm 5.2$ years, median evolution time was 36 [24, 69] months, overweight in $82.5 \%$ of patients). Clinical evaluation performed with the visual analog scale (VAS), Western Ontario and McMaster Osteoarthritis Index (WOMAC), Lequesne score, Get up and Go (GUG) and Timed up and Go (TUG) tests. The percentage of fat mass was measured using impedencemetry.

All subjects were instructed to perform sit-to-stand transfers during 30 secondes. We measured the speed, strength and muscular power of the lower limbs during this test using the Myotest $P R O \otimes$ accelerometer

A correlation analysis was performed in search of factors associated with physical performance alteration

Results: The median speed during the sit-to-stand test was 4.3 [3.1-6.2] cm / sec. The median muscular strength and power during this test were 15.2 [13.617.7] $\mathrm{Nm} / \mathrm{kg}$ and 14.5 [9.9-21.7] W / kg respectively.

Body mass index (BMI) correlated negatively with the 3 parameters of physivcal performance mesured by the Myotest $P R O \otimes$ accelerometer (speed, strength and muscle power) during the sit-to-stand test $(p<0,05)$. There was no correlation between those measured parameters of physical performance, pain and functional indices of knee osteoarthritis.

Conclusion: Our pilot study assessed the physical performance of the lower limbs in knee osteoarthritis patients, by measuring the speed, strength and muscle power during the the sit-to-stand test. It suggests an association between obesity and physical performance alteration in knee osteoarthritis patients.

Disclosure of Interests: None declared

DOI: 10.1136/annrheumdis-2020-eular.3352

\section{AB1286-HPR EXAMINATION OF DYNAMIC GRIP ENDURANCE RELATED FACTORS IN PATIENTS WITH PSORIATIC ARTHRITIS}

I. Naz Gürşan ${ }^{1}$, M. Köprülüoğlu' ${ }^{1}$, D. Solmaz², S. Akar². ${ }^{1}$ Izmir Katip Celebi University, Faculty of Health Sciences, Department of Physiotherapy and Rehabilitation, Izmir, Turkey; ${ }^{2}$ Izmir Katip Celebi University, Faculty of Medicine, Department of Rheumatology, Izmir, Turkey

Background: Psoriatic arthritis (PsA) is a disease manifested by destruction of articular cartilage, subchondral bone, and fibrosis of the joint capsule without excessive synovitis (1). Most of studies that examining hand in PsA are radiographic, ultrasonographic, magnetic resonance imaging research and there is little knowledge about functional assessment of hand. According to our knowledge, there is no study assessing grip endurance in patients with PsA.

Objectives: To assess dynamic grip endurance related factors in patients with PsA.

Methods: A total of 19 patients [Mean age; $53.5 \pm 12.6$ years, 14 women( $73.7 \%)$, 5 men(26.3\%)] diagnosed according to CASPAR criteria were included this study. Clinical and demographic characteristics were recorded. Dynamic grip endurance test was assessed with 10- repetition dynamic endurance test using a hand dynamometer (Lafayette Proffessional Hand Dynamometer, USA). Grip strength was examined by hand dynamometer and pinch strength was examined by pinchmeter (Lafayette, USA). Goniometer was used to assessment wrist position sense. Disability of Arm, Shoulder and Hand Survey (DASH) was used to determine disabilities and symptoms of upper extremity. We used Spearman's Rank Correlation Coefficient for data analysis.

Results: Dynamic grip endurance was negatively correlated with DASH score, perceived disability of hand, number of tender hand joints and positively correlated with grip strength, 3 point pinch strength on both dominant and non-dominant sides $(p<0.05$, Table 1). Dynamic grip endurance was not correlated with CRP level and joint position error on both dominant and non-dominant sides $(p>0.05)$.

Table 1. Examination Of Dynamic Grip Endurance Related Factors In Patients

\begin{tabular}{|c|c|c|c|c|}
\hline $\begin{array}{l}\text { Variables } \\
(n=19)\end{array}$ & $\begin{array}{l}\text { Dynamic Grip } \\
\text { Endurance } \\
\text { Dominant }\end{array}$ & $\begin{array}{l}\text { Dynamic Grip } \\
\text { Endurance } \\
\text { Dominant } \\
(\%)\end{array}$ & $\begin{array}{l}\text { Dynamic Grip } \\
\text { Endurance } \\
\text { Non- Dominant }\end{array}$ & $\begin{array}{c}\text { Dynamic Grip } \\
\text { Endurance } \\
\text { Non- } \\
\text { Dominant } \\
(\%)\end{array}$ \\
\hline DASH & $r=-0.525$ & $r=0.524$ & $r=-0.608$ & $r=0.153$ \\
\hline Perceived Disability & $r=-0.466$ & $r=0.326$ & $\begin{array}{l}\mathrm{r}=-0.509 \\
\mathrm{p}=0.026\end{array}$ & $r=0.414$ \\
\hline Pain in Hand Joints & $\begin{array}{l}r=-0.363 \\
p=0.127\end{array}$ & $\begin{array}{l}r=0.472 \\
p=0.041\end{array}$ & $\begin{array}{l}r=-0.316 \\
p=0.188\end{array}$ & $\begin{array}{l}r=0.542 \\
p=0.017\end{array}$ \\
\hline $\begin{array}{l}\text { Number Of Tender } \\
\text { Hand Joint }\end{array}$ & $\begin{array}{l}r=-0.641 \\
p=0.003\end{array}$ & $\begin{array}{l}r=0.569 \\
p=0.011\end{array}$ & $\begin{array}{l}r=-0.580 \\
p=0.009\end{array}$ & $\begin{array}{l}r=0.268 \\
p=0.267\end{array}$ \\
\hline Number Of Swollen & $\mathrm{r}=-0.349$ & $\begin{array}{l}r=0.359 \\
p=0.131\end{array}$ & $r=-0.526$ & $r=-0.094$ \\
\hline $\begin{array}{l}\text { Hand Joint } \\
\text { Joint Position Error }\end{array}$ & $\begin{array}{l}\mathrm{p}=0.143 \\
\mathrm{r}=0.147\end{array}$ & $\begin{array}{l}p=0.131 \\
r=-0.127\end{array}$ & $\begin{array}{l}p=0.021 \\
r=0.412\end{array}$ & $\begin{array}{l}p=0.702 \\
r=-0.026\end{array}$ \\
\hline Dominant & $\mathrm{p}=0.548$ & $p=0.606$ & $\mathrm{p}=0.080$ & $\mathrm{p}=0.915$ \\
\hline $\begin{array}{l}\text { Joint Position Error } \\
\text { Non-dominant }\end{array}$ & $\begin{array}{l}\mathrm{r}=0.213 \\
\mathrm{p}=0.381\end{array}$ & $\begin{array}{l}r=-0.339 \\
p=0.156\end{array}$ & $\begin{array}{l}r=0.047 \\
p=0.848\end{array}$ & $\begin{array}{l}r=0.350 \\
p=0.141\end{array}$ \\
\hline $\begin{array}{l}\text { Grip Strength } \\
\text { Dominant }\end{array}$ & $\begin{array}{l}r=0.960 \\
p<0.001\end{array}$ & $\begin{array}{l}r=0.033 \\
p=0.892\end{array}$ & $\begin{array}{c}r=0.722 \\
p<001\end{array}$ & $\begin{array}{l}r=-0.035 \\
p=0.887\end{array}$ \\
\hline $\begin{array}{l}\text { Grip Strength } \\
\text { Non- Dominant }\end{array}$ & $\begin{array}{l}r=0.742 \\
p<0.001\end{array}$ & $\begin{array}{l}r=-0.151 \\
p=0.538\end{array}$ & $\begin{array}{l}r=0.967 \\
p<0.001\end{array}$ & $\begin{array}{l}r=0.035 \\
p=0.887\end{array}$ \\
\hline 2 Point Dominant & $\begin{array}{l}r=0.134 \\
p=0.585\end{array}$ & $\begin{array}{l}r=-0.561 \\
p=0.012\end{array}$ & $\begin{array}{l}r=0.344 \\
p=0.149\end{array}$ & $\begin{array}{l}r=-0.240 \\
p=0.322\end{array}$ \\
\hline 3 Point Dominant & $\begin{array}{l}r=0.539 \\
p=0.017\end{array}$ & $\begin{array}{l}r=-0.444 \\
p=0.057\end{array}$ & $\begin{array}{l}r=0.752 \\
p<0.001\end{array}$ & $\begin{array}{l}r=-0.318 \\
p=0.185\end{array}$ \\
\hline Lateral Dominant & $\begin{array}{l}r=0.354 \\
p=0.137\end{array}$ & $\begin{array}{l}r=-0.516 \\
p=0.024\end{array}$ & $\begin{array}{l}r=0.355 \\
p=0.136\end{array}$ & $\begin{array}{l}r=-0.116 \\
p=0.637\end{array}$ \\
\hline 2 Point & $r=0.622$ & $r=-0.200$ & $r=0.742$ & $r=0.031$ \\
\hline Non-Dominant & $p=0.004$ & $p=0.411$ & $p<0.001$ & $\mathrm{p}=0.901$ \\
\hline Non Dominant & $\mathrm{p}=0.004$ & $\mathrm{p}=0.375$ & $p<0.001$ & $\mathrm{p}=0.957$ \\
\hline $\begin{array}{l}\text { Lateral } \\
\text { Non Dominant }\end{array}$ & $\begin{array}{l}r=0.459 \\
p=0.048\end{array}$ & $\begin{array}{l}r=-0.366 \\
p=0.123\end{array}$ & $\begin{array}{l}r=0.579 \\
p=0.009\end{array}$ & $\begin{array}{l}r=-0.063 \\
p=0.783\end{array}$ \\
\hline CRP & $\begin{array}{l}r=-0.280 \\
p=0.246\end{array}$ & $\begin{array}{l}r=-0.008 \\
p=0.974\end{array}$ & $\begin{array}{l}r=-0.386 \\
p=0.102\end{array}$ & $\begin{array}{l}r=0.023 \\
p=0.926\end{array}$ \\
\hline
\end{tabular}

DASH: Disability of Arm, Shoulder and Hand Survey, ${ }^{\star}$ Spearman Correlation Test

Conclusion: Our findings suggest that dynamic grip endurance is associated with different functional parameters of the hand and worsening clinical parameters. Examining dynamic grip endurance might be a guide in creating an exercise program for clinicans in rehabilitation of patients with PsA

References:

[1] BELSKY, Mark R., et al. Hand involvement in psoriatic arthritis. The Journal of hand surgery, 1982, 7.2: 203-207.

Disclosure of Interests: None declared

DOI: 10.1136/annrheumdis-2020-eular.3317

\section{AB1287-HPR INVESTIGATION OF THE RELATIONSHIP BETWEEN GRIP ENDURANCE, DISABILITY OF UPPER EXTREMITY AND QUALITY OF LIFE IN PATIENTS WITH RHEUMATOID ARTHRITIS}

M. Köprülüoğlu ${ }^{1}$, I. Naz Gürşan ${ }^{1}$, D. Solmaz ${ }^{2}$, G. Kabadayi ${ }^{2}$, H. Cinakli², S. Akar ${ }^{2}{ }^{1}$ Izmir Katip Celebi University, Faculty of Health Sciences, Department of Physiotherapy and Rehabilitation, Izmir, Turkey; ${ }^{2}$ Izmir Katip Celebi University, Faculty of Medicine, Department of Rheumatology, Izmir, Turkey

Background: Upper extremity functions affect the quality of life at different levels in patients with rheumatoid arthritis (RA). In the current literature; it has been shown that grip endurance is associated with upper limb functions (1). However there is no study investigating the relationship between grip endurance and quality of life in patients with RA.

Objectives: To investigate relationship between grip endurance, disability of upper extremity and quality of life in patients with RA. 